\title{
La muerte de Salmerón y las fracturas del republicanismo: septiembre de 1908
}

\author{
MARTIN MUÑOZ ZAFRA \\ CEHME
}

\author{
Salmerón's death and republican cleavages: \\ september 1908
}

\begin{abstract}
RESUMEN
A principios del siglo XX los partidos republicanos adquieren relevancia sólo en cuanto se incorporan a una lucha simbólica en búsqueda del progreso y la moralidad. Las diversas reacciones a la muerte de Salmerón nos muestran las brechas que corroen la unidad del republicanismo.

PALABRAS CLAVE Republicanismo, huérfanos de la moralidad, rupturas, etnocentrismo, poder, prensa, interaccionismo simbólico.
\end{abstract}

\section{ABSTRACT}

In the early $20^{\text {th }}$ century the local republicans parties acquire meaning only insofar as they can be subsumed in a symbolic fight in search of progress and morality. Salmerón's death reactions show us the various cleavages through which republicanism unity is undermined.

\section{KEY WORDS}

Republicanism, orphans of morality, cleavages, ethnocentrism, power, press, symbolic interactionism.

«Luego todos son absolutistas..., y toda su emancipación consiste en dejar de creer en el Papa para creer en Salmerón o en cualquier fabricante de frases por el estilo... A nosotros nos odian porque ya discurrimos sin necesidad de ellos. ${ }^{1}$ ale? $»^{2}$

"Dost thou think because thou art virtuous there shall be no more cakes and

1 BAROJA Y NESSI, P.: Aurora roja. Madrid, Alianza Editorial, 2005, p. 159.

2 SHAKESPEARE, W. 1601: Twelth Night, II, 3. 


\section{INTRODUCCIÓN: CLEAVAGES}

Para una gran parte de los republicanos españoles de la época, Nicolás Salmerón tuvo, en los últimos años de su vida, una actuación política cercana a la deslealtad. En muchas de las reseñas recogidas en los órganos republicanos menos propensos a las aproximaciones catalanistas del Jefe de la Unión se pedía, en el mejor de los casos, respeto y silencio ante su desaparición, y ello debido sólo a su protagonismo en la evolución del republicanismo histórico y, especialmente, por sus virtudes cívicas y morales.

Antes y después de su muerte, las reacciones ante la labor política de Salmerón al frente de la Solidaridad fueron objeto de debate en las distintas facciones de la prensa republicana, formando un tejido crítico de singular interés. Recordemos que en numerosas circunstancias un historiador actúa como manipulador u operador de símbolos.

Todos los datos, fuentes, son producidos socialmente, ninguno puede ser tratado de forma neutral o como si fuera una encarnación lúcida de la realidad. Los investigadores no deberíamos suponer que existan informaciones libres de cualquier sesgo. Como eso, al parecer, no existe, se trataría, en cambio, de indagar la forma de interpretar cabalmente cualquier tipo de datos que caiga en nuestras manos ${ }^{3}$.

En 1908 las reacciones a la muerte de Salmerón nos muestran las distintas brechas o rupturas sociopolíticas que corroen al republicanismo español o, si se quiere, a los distintos republicanismos del momento, fisuras igualmente reconocibles en toda la articulación del espectro político y social del Estado.

El término cleavage, fractura o ruptura, es útil para la explicación de una serie de pautas de conflicto dentro de los sistemas políticos que, en definitiva, expresan un mantenimiento o modificación de los valores u orientaciones de los ciudadanos. Estas rupturas del tejido político que pueden conducir a un conflicto son, fundamentalemente en su tipología, cuatro modelos: el religioso, el étnico-lingüístico, el socio-económico y el regional centro-periferia ${ }^{4}$. Todos ellos pueden reconocerse en la quiebra del inestable republicanismo que surgió tras la frágil, aunque propicia, Unión de 1903 y en algunas de sus consecuencias. Uno de los efectos de esta inestabilidad orgánica fue la aparición, agraciada por la Ley de Jurisdicciones de 1906, de la Solidaridad Catalana, construcción y amalgama que posiblemente en el fondo sólo persiguiera la pureza de la vida política pero con matices de carácter nacionalista, periférico, burgués e incluso clerical. Estos componentes precisamente son los que se reconocen en las rupturas políticas a las que nos hemos referido y que se despliegan en el conflicto más importante que desmembró el universo re-

${ }^{3}$ HAMMERSLEY, M. y ATKINSON, P.: Etnografía. Métodos de investigación. Barcelona, Paidós, 1994 , pp. 188 y 148.

4 Un análisis conciso en el clásico RAE, D. W. y TAYLOR, M.: The Analysis of Political Cleavages. New Haven y Londres, Yale University Press, 1970, 152 pp. 
publicano a principios de siglo. Se debe recalcar, no obstante, que la quiebra del republicanismo en aquellos años, añádase la inercia de abundantes desencuentros, no sólo fue consecuencia de la confrontación entre Solidarios y Antisolidarios, sino que ya algunos de los elementos más jóvenes que integraron la Unión de 1903, concebían estrategias más revolucionarias que las propugnadas por Nicolás Salmerón a través de la vía parlamentaria y la educación cívica. Así, Vicente Blasco declaraba en un mitin en Asturias que, una vez muerto Sagasta, "es menester que viva prepotente la organización republicana» ${ }^{5}$. Azcárate dilucidó los precedentes de esta situación de conflicto en la primera sesión de la Junta Nacional de 1907:

«La indisciplina en que se encuentran ciertos elementos de Unión Republicana, es anterior a la Solidaridad Catalana y se personifica en cuantos levantan la bandera de la revolución. (...) Que este espectáculo no puede continuar sin que se incapacite al partido republicano para el gobierno del país. Y por último que incluso para un movimiento de fuerza hace falta inspirar confianza a los que lo han de producir, confianza que jamás se engendrará al ver cómo nos dividimos y devoramos mutuamente» 6

El enfrentamiento entre los lerrouxistas y los solidarios del jefe Salmerón, no sólo acabó con la Unión de 1903 sino que fructificó en la plasmación del Partido Radical de Lerroux en febrero de 1908 y del Bloque de Izquierdas que promoviese Melquíades Álvarez meses después. Según Carmen Amate el experimento unificador de 1903, «desde el punto de vista personal lo podemos interpretar como un período de relanzamiento, de fulgor casi romántico, del experimentado político que era don Nicolás " ${ }^{7}$.

La Unión de 1903 intentó ser la última opción de un republicanismo unido bajo el lema del parlamentarismo y la regeneración nacional ${ }^{8}$. Esta persecución de la moralidad y la regeneración nacional es lo que intentó Salmerón extrapolar desde la Solidaridad al resto del mundo republicano. En la última sesión de la Junta de 1907, dedicada a debatir la cuestión de la Solidaridad, Corominas pudo definirla como «procedimiento para obtener una finalidad: inutilizar, derribar el régimen vigente. Por eso lo que al presente se limita a ser solidaridad catalana ha de llegar un día a ser Solidaridad española» ${ }^{9}$. Pero los republicanos también su-

5 «La Unión Republicana. El mitin de Castillón», El Noroeste, Gijón, 7 de enero de 1903, p. 3. Blasco no justifica el anarquismo, pero no equipara la ferocidad del carlismo con el fanatismo terrorista. «Dos peligros», en Obras Completas, VI. Madrid, Aguilar, p. 1144.

6 «Junta Nacional de Unión Republicana. Actas de la sesiones celebradas los días 25, 26 y 27 de febrero de 1907», El País, Madrid, 9 de marzo de 1907, p. 3.

7 AMATE MARTÍNEZ, C.: Entre la historia y el mito. Nicolás Salmerón y la masonería española, en FERRER BENIMELI, J. A. (coord.) La masonería española en la época de Sagasta. Zaragoza, CEHMEGobierno de Aragón, 2007, p. 491.

8 Véase DUARTE, Á.: «La unión republicana de 1903 ¿eslabón o gozne?», en MARTíNEZ LÓPEZ, F. (ed.) Nicolás Salmerón y el republicanismo parlamentario. Madrid, Biblioteca Nueva, 2007, pp. 147163.

9 «Junta Nacional de Unión Republicana. Actas de la sesiones celebradas los días 25, 26 y 27 de febrero de 1907», El País, Madrid, 9 de marzo de 1907, p. 4. 
frían la incomprensión del socialismo. Éste se quejaba de que algunos prohombres republicanos les acusaran de no colaborar en el derrocamiento de la monarquía:

«Pues si ese sambenito nos han colgado, ¿qué dirán de Salmerón engendrador de la Solidaridad Catalana, perturbador de la Unión que acaudillaba y causante de la parálisis que dicha Unión ha sufrido en el Congreso?» ${ }^{10}$

En cualquier caso la Unión de 1903 ya nacía con cierto riesgo de desavenencias. La portada de ;Cu-Cut! de aquellos días nos ilustra a un Salmerón que proclama la unidad de unos republicanos que se entienden a golpes ${ }^{11}$ :

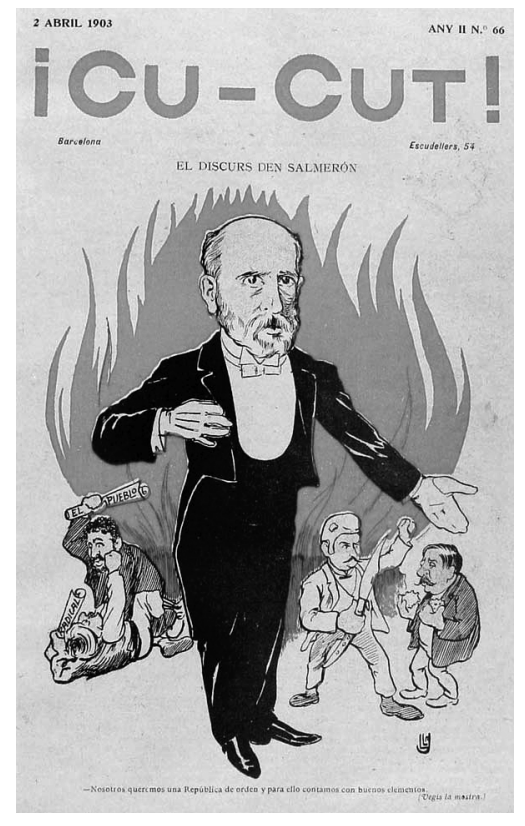

Para los socialistas la Unión de 1903 era una mezcla de republicanos muy conservadores y republicanos presuntuosos de estar en los límites de la anarquía. Pero allí faltan parte de los republicanos progresistas «y faltan, sobre todo, los que han constituido el grupo más numeroso y más sano de la familia republicana española: la casi totalidad de los republicanos federales ${ }^{12}$.

Tal como señaló Suárez Cortina, el apoyo de Salmerón a la Solidaridad Catalana y la confrontación con Lerroux están en el origen del Partido Radical (1908),

10 ¡Pícaros socialistas!, El Socialista, 28 de junio de 1907, pág. 2.

11 «Nosotros queremos una República de orden y para ello contamos con buenos elementos. (Vegís la mostra)». ¡Cu-Cut!, Barcelona, núm. 66, 2 de abril de 1903.

12 «El nuevo partido republicano», El Socialista, 3 de abril de 1903. 
«pero denotan sobre todo, la persistencia en el interior de la Unión de dos culturas políticas distintas: la radical y la reformista» ${ }^{13}$. La demagogia de Lerroux se expresa en la siguiente frase que exhibe todo el marco y polaridades del conflicto: «Si hubiera sido militar, hubiera ido a quemar La Veu, el Cu-Cut!, la Lliga y el palacio del obispo, por lo menos... ${ }^{14}$

Cuatro principales cleavages vamos a comentar aquí: el producido entre solidarios y lerrouxistas, el reconocido entre españolistas-centristas y nacionalistas catalanes, el clerical-anticlerical y el que sutilmente puede admitirse en el seno del Gran Oriente Español entre salmeronianos y facciones más progresistas del republicanismo. Desde luego existe un solapamiento funcional entre algunos de ellos. Además, podría considerarse alguna otra «ruptura» social, como la señalada por Juan Avilés: estando Lerroux fuera de España, "comenzó en el otoño de 1908 una sorda lucha entre anarquistas y radicales por el control del movimiento obrero catalán ${ }^{15}$.

Para el republicanismo más radical, españolista y antisolidario, Salmerón es el enemigo de la patria, el destructor de la Unión Republicana y el traidor al pueblo. Esta definición era especialmente dolorosa para el republicanismo catalanista. Éste se lamentaba de que «l'odi, sempre l'odi» ${ }^{16}$ fuera protagonista, incluso ante el féretro del jefe.

Sin verse desde hacía siete años, el republicano de derechas Juan Sol y el republicano de izquierdas Alejandro Lerroux resultaron unidos frente a la Solidaridad. En enero de 1909 Sol y Ortega sostenía en el Senado que «el Sr. Salmerón entró en Solidaridad a título de español, creyendo de buena fe que prestaba un servicio a su país; pero que los demás republicanos, excepto el Sr. De Buen, todos son más o menos nacionalistas » ${ }^{17}$. Por su parte Lerroux evocaba:

«Habíame derrotado en Barcelona la Solidaridad de republicanos claudicantes, catalanistas de todos los matices, clericales de todas layas y carlistas, en mezcolanza inverosímil. Había perdido la representación parlamentaria. Acababa de fundar La Casa del Pueblo y mi periódico El Progreso. Por toda la región se organizaron a centenares Centros republicanos que adoptaron la simpática denominación de Fraternidades, muchas de ellas domiciliadas en edificio propio a base de escuelas, cooperativas, coros y orfeones y otras instituciones de carácter social y de

13 SUÁREZ CORTINA, M.: «El reformismo institucionalista. La cultura política del republicanismo de cátedra», en MORALES MUÑOZ, M. (ed.) República y modernidad. El republicanismo en los umbrales del siglo XX. Málaga, CEDMA, 2006, pp. 56-57.

14 «El alma en los labios», La Publicidad, Barcelona, 9 de diciembre de 1905. Según Álvarez Junco la retórica de Lerroux «se apoyaba más en su emotividad y su estética que en su capacidad racionalizadora». ÁLVAREZ JUNCO, J.: El Emperador del Paralelo. Lerroux y la demagogia populista. Madrid, Alianza Editorial, 1990, p. 264.

${ }_{15}$ AVILÉS FARRÉ, J. : Francisco Ferrer y Guardia. Pedagogo, anarquista y mártir. Madrid, Marcial Pons, 2006, p. 208.

16 «La Setmana», La Campana de Gracia, Barcelona, 26 de septiembre de 1908, p. 2.

17 Palabras de Sol y Ortega en el Senado el 27 de enero de 1909. Citado en TATO Y AMAT, M.: Sol y Ortega y la política contemporánea. Madrid, Imprenta Artística Española, 1914, p. 391. 
asistencia y socorro mutuos. Toda aquella fructificación de mis campañas iba a malograrse no sólo en Cataluña, sino en casi toda España, si yo no la recogía, la unificaba, la plasmaba en una organización nacional» ${ }^{18}$.

En una de sus primeras intervenciones en la Junta de 1907 Nicolás Salmerón dijo que «a tal extremo ha llegado esa lucha, que se ha podido decir con una expresión que lacera mi alma, que los que combaten en Barcelona son kábilas». Y lo decía con dolor porque consideraba la democracia de Barcelona como modelo sin igual en España y casi en Europa. Lerroux le contestó que si había violencia era justa y precisa, ya que «frente a la masa republicana se levanta la ofensa intolerable de un partido clerical y carlista que antes ni siquiera se atrevía a manifestarse ${ }^{19}$. La Campana de Gracia escribe al respecto: «Fou menester tota la serenitat de aquest poble para que la primera ciutat d'Espanya per son esperit democrátich, no quedés convertida en una tribu de salvatjes ${ }^{20}$.

Muestra de la desmembración en el espacio politico catalán es la hostilidad entre el semanario de Cambó y El Progreso que se revela en el órgano radical autonomista de Gerona: «Para vivir con holgura y sin trabajo ya sabemos lo que hay que hacer. Meterse a solidario archivando antes la conciencia en una alcantari$\| l a{ }^{21}$. En el núcleo republicano de Rubí la división era probada:

«El procés que comença amb els coneguts fets del Cu-cut! i continua amb la Llei de jurisdiccions i la Solidaritat Catalana dividirà el republicanisme català i decantarà els republicans rubinencs, que durant tot el 1905 ja han estat enfrontats una mica confusament, en dos sectors clars»22.

La tensión entre solidarios y lerrouxistas se agravaría durante la campaña para la elección de diputados a Cortes de 21 de abril de 1907. El día 18 se produjo un atentado en Barcelona contra el republicano solidario Salmerón y el regionalista Cambó: las sospechas caen sobre los lerrouxistas, «partidarios exaltados de Lerroux» ${ }^{23}$. Salmerón había recibido un anónimo días antes. Tras el atentado declaró: «Mal me conocen mis enemigos si creen que pueden avasallarme con el terror ${ }^{24}$. Al día siguiente, estando Lerroux en Rubí y en casa de Palet, estuvo cer-

18 LERROUX, A.: Mis memorias. Madrid, Afrodisio Aguado, 1963, p. 434. Lerroux es definido como «un faranduler de la revolució». «Finis coronat opus», La Campana de Gracia, Barcelona, 2 de marzo de 1907, p. 2.

19 «Junta Nacional de Unión Republicana. Actas de la sesiones celebradas los días 25, 26 y 27 de febrero de 1907», El País, Madrid, 9 de marzo de 1907, p. 3.

20 «Finis coronat opus», La Campana de Gracia, Barcelona, 2 de marzo de 1907, p. 2.

21 «Moralidad Solidaria», Bandera Roja, Gerona, 20 de septiembre 1908, pp. 2-3.

22 BATALLA I GALIMANY, R.: Els casinos republicans: política, cultura i esbarjo. El casino de Rubí, 1884-1939. Barcelona, Publicacions de I'Abadia de Montserrat, 1999, p. 93.

${ }^{23}$ NÚÑ̃EZ FLORENCIO, R.: El terrorismo anarquista (1888-1909). Madrid, Siglo XXI de España Editores, 1983, p. 127. El enaltecimiento de la acción en el manifiesto de Lerroux «Rebeldes, rebeldes», en La Rebeldía, Barcelona, 1 de septiembre de 1906.

24 «Desórdenes en Barcelona. Atentado contra Salmerón», El Noroeste, Gijón, 20 de abril de 1907, pág.1. 
cado dieciocho horas por una muchedumbre que resolvió «rociar las paredes de la casa con petróleo y prenderles fuego ${ }^{25}$.

La fractura centro-periferia se hace patente a través de las palabras del antisolidario Juan Sol, que ponía de manifiesto la falacia de los solidarios que dicen una cosa en Cataluña y otra en Madrid. Para el republicanismo malagueño la Solidaridad Catalana era «esa amalgama híbrida y perniciosa para el republicanismo español», que se interponía entre Salmerón y sus correligionarios ${ }^{26}$.

El modelo centro-periferia parece articular el artefacto político Solidaridad como herramienta entre los centros de poder del momento y el pueblo. Frente al radicalismo populista de Lerroux, frente al republicanismo revitalizador de la moral civil, el poder central, ambiguamente sugiere alimentar a la Solidaridad como instrumento neutralizador de una cultura mítica republicana. Se nos presenta la Solidaridad como mecanismo organizador de tensiones, como el patrón State-Church según el evolucionismo del postboasiano Leslie White ${ }^{27}$. Esta ambigüedad en la acción política la hizo pública Sol y Ortega cuando afirmaba que la Solidaridad «ha tirado dos años mediante esta serie de equívocos y mediante el amparo del Sr. Maura», Maura quien, "para halagar a los solidarios, llevó al rey a Barcelona» ${ }^{28}$. Así, la tensión centro-periferia, articulada por el poder central, persigue socavar en ambas direcciones todo cuanto inquiete la violencia simbólica orientada desde Madrid $^{29}$.

El 19 de septiembre de 1908 Alejandro Lerroux embarcaría en Marsella con destino a Buenos Aires. Perseguido por Maura y La Cierva hacía caso de los consejos de Sol y Ortega: que buscara su salvación por la frontera pues las cárceles españolas no eran seguras para él. El librepensador Ferrer y Guardia estaba interesado en este viaje de Lerroux a Sudamérica pues allí podría hallar apoyos para un movimiento revolucionario ${ }^{30}$. El día 20 Alejandro Lerroux se refugia, procedente de Marsella, en Gibraltar. En Gerona la prensa adicta proclama «Lerroux es Cromwell» ${ }^{31}$.

La escalada del catalanismo se afianza con el establecimiento de Solidaridad Catalana, de la que se excluyen los lerrouxistas. El triunfo de la Solidaridad en las elecciones de abril de 1907 proporcionó cierta preeminencia al nacionalismo catalán y la quiebra del republicanismo españolista en Cataluña. El impulso de Salmerón a Solidaridad Catalana procede de la concepción de ésta como motor movilizador de la vida política en el contexto de la crisis de representatividad del

25 «Solidarios y antisolidarios. Las represalias», El Noroeste, Gijón, 21 de abril de 1907.

26 «iPaz a los muertos!», El Popular, Málaga, 22 de septiembre de 1908, p. 1.

27 WHITE, L.: The Evolution of Culture. Nueva York, McGraw Hill, 1959, pp. 313-314.

28 TATO Y AMAT, M. 1914: p. 391.

${ }_{29}$ Sobre Bourdieu y la violencia simbólica véase TAROT, C.8: Le symbolique et le sacré. Théories de la religion. París, Éditions La Découverte/M.A.U.S.S., 2008, pp. 427-450.

30 AVILÉS FARRÉ, J. 2006: pág. 208.p

31 «Lerroux y el gobierno», Bandera Roja, Gerona, 13 de septiembre de 1908, p. 2. 
Estado de la Restauración. Incluso Corominas lo recalcaría de esa forma en la Junta Nacional de febrero de 1907 afirmando que «la Solidaridad Catalana es altamente beneficiosa para España por cuanto ha realizado obra de pacificación, de progreso y republicanismo $\gg 32$.

En enero de 1909 Sol y Ortega le decía a De Buen que los republicanos que formaban en la Solidaridad si no eran francamente nacionalistas, desde luego sí simpatizaban con ellos, y que la Solidaridad «se componía de catalanistas, católicos políticos, carlistas y algunos republicanos, y que estaba disuelta y desvencijada y que mantenía cuanto había dicho de la pretensión de las nacionalidades con la hegemonía de Cataluña»33.

El modelo de Salmerón quiere ser trasladado a otras regiones españolas, claro que ya no es la fórmula catalana (republicanos, regionalistas y carlistas), sino la escrupulosamente republicana, con el objeto de extender por el Estado la regeneración, la moralidad, la modernización y la pureza en el sufragio. Así, el domingo 1 de julio de 1906, se celebró en el teatro Eslava de Sevilla un mitin organizado por los republicanos de la región para sellar el pacto de solidaridad convenido anteriormente en Madrid. Allí se nombró una ponencia llamada Junta Regional Andaluza de Unión Republicana con objeto de crear la solidaridad en la región. Y allí se recibió un revelador telegrama de Salmerón que decía:

«Saludo cordialmente representantes republicanos solidaridad andaluza. Constituyan órgano sano, vigoroso, para cooperar acción redentora patria, exterminando caciquismo, imponiendo a poderes Estado soberanía pueblo y afirmando solidaridad nacional sobre robustez autonomía regiones» ${ }^{34}$.

Pero los dirigentes republicanos andaluces hablaron del mundo obrero, de revolución, de posturas no separatistas, de gestos enérgicos y de esfuerzos, todo ello con matices poco unánimes, de ahí su carácter efímero. Montes Sierra declaró después ante la Junta Nacional que la Unión Republicana sevillana era abiertamente contraria a la Solidaridad ${ }^{35}$.

La imagen del periodismo republicano en la redacción de El Motín a comienzos de siglo se exhibe en las páginas de Rafael Cansinos. En «aquella capilla en ruinas del culto a la República» Nakens en esos días «trataba en vano de exaltar la figura de Salmerón y rehacer sobre esa base la unidad del partido". Junto a él otros periodistas como Nicolás Díaz Pérez, Brieva o José Cintora, simb. Leónidas, se dedicaban a comentar recurrentemente «la impotencia de los republicanos y sus

32 «Junta Nacional de Unión Republicana. Actas de las Sesiones celebradas los días 25, 26 y 27 de febrero de 1907», El País, Madrid, 9 de marzo de 1907, p. 3.

33 TATO Y AMAT, M. 1914: p. 399.

34 «Mitin en Sevilla. La solidaridad republicana de la región andaluza», El Popular, Málaga, 3 de julio de 1906.

35 «Junta Nacional de Unión Republicana. Actas de las sesiones celebradas los días 25, 26 y 27 de febrero de 1907», El País, Madrid, 9 de marzo de 1907, p. 4. 
achaques físicos de catarrosos y gastríticos» ${ }^{36}$. A comienzos de siglo la imagen del republicanismo la vislumbra Ernesto Sawa en la redacción de Don Quijote:

«Yo la he visto - en mis fiebres imaginativas - semejante a una de esas heroínas de las leyendas, el pelo suelto sobre la espalda, la mirada llameante, las vestiduras rotas, manchada de sangre, indignada y furiosa — ¡la trágica, pero hermosura figura de la Revolución!

Y he visto después a la fogosa heroína transformada en plácida matrona; la alba túnica cayéndole en pliegues sobre los pies, como en las estatuas de las diosas, la mirada serena y tranquila, la boca sonriente sosteniendo en sus manos la balanza y la espada, símbolos de la justicia y de la fortaleza.

Así, bajo esos dos aspectos, tan extrañamente distintos, he visto siempre a la República, representando... primero a la Revolución, representando después el Poder...»37

La proximidad de Salmerón a la masonería ha sido muy discutida y no demostrada. Se ha escrito sobre un supuesto ofrecimiento de la Orden al líder republicano hacia el año 1887 con el objeto de promover su iniciación, incluso algunos investigadores la han deducido de la iconografía masónica de su mausoleo ${ }^{38}$. Se ha señalado la relación entre el anquisolado republicanismo histórico, los «gubernamentales», como Salmerón, Azcárate, Morayta y la cúpula del Gran Oriente Español (GOE), así como las expectativas sobre la evolución y directrices del recientemente creado Partido Republicano Radical en 1908. Recordemos las relaciones de Lerroux con Francisco Ferrer. Se trata de un republicanismo anticlerical, con referencia al radicalismo masónico francés, que produce cierta incomodidad en la cúpula del Gran Oriente Español identificada con Salmerón ${ }^{39}$. Un enfrentamiento, pues, entre dos sensibilidades republicanas a través del GOE, una soterrada y oscura lucha «entre los masones radicales y los masones dirigentes salmeronianos ${ }^{40}$. Nos encontramos ante la búsqueda de modelos externos, la reinterpretación de una cultura masónica en el republicanismo

${ }^{36}$ CANSINOS ASSENS, R.: La novela de un literato, I. Madrid, Alianza Editorial, 2005, pp. 53-54. La prensa republicana como instrumento en ARCAS CUBERO, F.: «El republicanismo en Andalucía hasta la Segunda República (1868-1931)», en MARTÍNEZ LÓPEZ, F. (ed.) Nicolás Salmerón y el republicanismo parlamentario. Madrid, Biblioteca Nueva, 2007, pp. 232-234.

37 «La República», Don Quijote, Madrid, 6 de junio de 1902, p. 4.

38 AMATE MARTíNEZ, C.: Entre la historia y el mito. Nicolás Salmerón y la masonería española, en FERRER BENIMELI, J. A. (coord.) La masonería española en la época de Sagasta. Zaragoza, CEHMEGobierno de Aragón, 2007, p. 497. Además, «Nicolás Salmerón y su presunta vinculación con la masonería», ponencia presentada por José Antonio Ferrer Benimeli en el XII Symposium Internacional de Historia de la Masonería Española, Almería, 8-10 de octubre de 2009. También, VALíN FERNÁNDEZ, A.: Masonería y revolución. Santa Cruz de Tenerife, Ediciones Idea, 2008, 313 pp.

${ }_{39}$ Sobre el arraigo de la laicidad en la Tercera República véase PELLISTRANDI, B.: «Clericalismo y anticlericalismo en Francia. ¿Una denominación de origen? », en DE LA CUEVA MERINO y MONTERO GARCÍA, F. (eds.) La secularización conflictiva. España (1898-1931). Madrid, Biblioteca Nueva, 2007, pp. 23-38.

40 MARTÍN MARTÍNEZ L. P.: Los arquitectos de la República. Los masones y la política en España. Madrid, Marcial Pons, 2007, pp. 53-54. 
radical ${ }^{41}$. Pero en las páginas de La Campana de Gracia se nos recuerda que los traidores al pueblo son los que se disfrazan de revolucionarios y lo explotan ${ }^{42}$.

Un sector de la masonería solicita la rectitud, el respeto y la integridad de juicio sobre el cadáver de un Salmerón casi difamado:

«Calientes todavía los restos del gigante, ha habido ya quien iniciara críticas necias o infames sobre sus últimos actos políticos. ¿Porqué no ha de poderse embalsamar el cadáver histórico, como el real, para librarle también de los gusanos? ¡Compadecemos la pequeñez de ciertas almas, y nos recogemos a lamentar la gran desgracia nacional en el silencio de los dolores íntimos!» ${ }^{43}$.

La fractura clerical-anticlerical es más espesa y menos evidente por el fuerte carácter anticlerical de algunos sectores catalanistas ${ }^{44}$. El antisolidario Sol y Ortega afirmaba cumplir el mandato de sus electores que le apremiaban:

«No vote usted en modo alguno el proyecto de Administración local y provincial, porque este proyecto, dado el estado de derecho público vigente en España, daría el triunfo al clericalismo, a la reacción, acabaría con la libertad y con todas las conquistas modernas y sería el sepulcro de todas las libertades conquistadas ${ }^{45}$.

Pero también Salmerón quiso recalcar en su discurso ante la Asamblea republicana de 1903 cuáles eran los enemigos de la civilización ${ }^{46}$.

La amenaza del clericalismo va ligada a la tibieza de muchos republicanos, y en las páginas de Andalucía Masónica se lee: «Y los que republicanos, se quedaron, ¿qué hicieron? Castelar, alardes de neo; Pí, encerrarse en su gabinete; Salmerón, equilibrios declamatorios y hueros » 47 . Por lo demás, no faltaban matices de un anticlericalismo propugnado por la Orden en aquellos momentos:

41 MARTÍN MARTÍNEZ, L. P.: «Modelos y culturas políticas en la masonería española contemporánea», en Stvdia Historica. Historia Contemporánea, núm. 2008, 23, p. 98. Véanse Actas del Consejo de la Orden de la Federación del Gran Oriente Español, Madrid, 15 y 18 de diciembre de 1906. Centro Documental de la Memoria Histórica, Salamanca (en adelante, CDMH), leg. 650A.

42 «Els traydors al poble son els que, disfressats de revolucionari, l'explotan y jugan ab ell com ab un infelís criatura». La Setmana», La Campana de Gracia, Barcelona, 26 de septiembre de 1908, p. 2.

43 «Salmerón», Andalucía Masónica, Málaga, 31 de septiembre de 1908, pág. 8.

${ }^{44}$ La movilización de la protesta anticlerical en SALOMÓN CHÉLIZ, M. P.: «El anticlericalismo en la caIle. Republicanismo, populismo, radicalismo y protesta popular (1898-1913)", en DE LA CUEVA MERINO y MONTERO GARCIA, F. (eds.) La secularización conflictiva. España (1898-1931). Madrid, Biblioteca Nueva, 2007, pp. 129-135. Anticlericalismo y acción política en CASTRO ALFÍN, D.: «Cultura, política y cultura política en la violencia anticlerical», en CRUZ, R. y PÉREZ LEDESMA, R. (eds.) Cultura y movilización en la España contemporánea. Madrid, Alianza Editorial, 1997, pp. 69-97. Además, DE LA CUEVA MERINO, J. 7: «Movilización política e identidad anticlerical», en Ayer, núm. 27, 1997, pp. 101-125.

45 TATO Y AMAT, M. 1914: p. 393.

46 «Hay obras que no podemos acometer, pero que podemos poner en camino de que lleguen a realizarse, y son aquellas que pongan al pueblo en el camino de la civilización, evitando que se arrastren a las gradas del Vaticano la dignidad nacional por los intereses del jesuitismo. Eso podemos y debemos hacerlo. La impía alianza del altar y del trono es forzoso que tenga un límite con la resurrección de España». «Discurso de Don Nicolás Salmerón», El Pueblo, Tortosa, 28 de marzo de 1903, p. 2.

47 «Nuestras cobardías ante la Iglesia tirana», Andalucía Masónica, núm. 29, Málaga, 19 de septiembre de 1910, p. 5. 
«La [plancha] 5096 de la Sociedad anticlerical solicitando una suscripción para atender a sus gastos. Se acuerda contribuir con la cantidad de cincuenta pesetas mensuales por ahora» ${ }^{48}$.

La búsqueda de la moralidad no va desligada de la instrucción racional. Es algo más que hacer ciudadanos: es «hacerlos hermanos de una sociedad mejor» ${ }^{49}$. Los fines de la educación racionalista no concuerdan con el matiz ideológico que despliegan algunos sectores de la Solidaridad, que se convierten en lastre al progreso, que impiden la regeneración del hombre por la escuela y la ciencia:

«En España constituyen un obstáculo a tan hermosa denominación, en primer término los carlistas y ultramontanos, por no decir los católicos, que tienen por dogma la intolerancia con todos lo que no piensan como ellos, porque son los únicos que creen poseer la verdad» 50 .

El jefe de la Solidaridad muere en Pau a donde fue a descansar, aunque se decía que iba a pasar el invierno en Málaga ${ }^{51}$. Aquí la Juventud Republicana se olvidó del jefe y, atenta al calendario republicano, se preparaba para conmemorar el cuadragésimo aniversario de la revolución de septiembre esperando una nueva época de concordia entre los republicanos: «El gobierno jesuítico de Maura, a la vez que hace hipócritas alardes de liberalismo, dispensa la más descarada protección a los carlistas y clericales de todo jaez» ${ }^{52}$.

\section{LA VISIÓN DE LA PRENSA}

Gabriel Alomar, en su alabanza a Salmerón, señalaba que lo más característico de éste «era la unidad e integridad entre el hombre y el político»53.

Los núcleos dirigentes republicanos procedían de aquellos sectores de las burguesías locales mercantiles no integrados en la política restauracionista. Por medio de la prensa quisieron acercar a la sociedad sus ideales ilustrados y su fe en la ciencia y la cultura ${ }^{54}$.

Los solidarios ganaron las elecciones de abril de 1907 «merced al atentado de Hostafranchs» ${ }^{55}$, afirmaba Juan Sol y Ortega, pero esta acusación era articulada

\footnotetext{
48 Actas del Consejo de la Orden de la Federación del Gran Oriente Español, Madrid, 26 de enero de 1907. CDMH, leg. 650A.

49 «La Escuela Moderna», en Boletín Oficial de la Gran Logia Simbólica Regional Catalana-Balear, núm. 17-18. Barcelona, 31 de diciembre de 1901, pp. 19-21.

50 "Qué es la República», Andalucía Masónica, Málaga, 30 de noviembre de 1908, p. 12.

51 «Don Nicolás Salmerón», La Coalición, Badajoz, 22 de septiembre de 1908.

52 «Por los mártires de la libertad», El Popular, Málaga, 26 de septiembre de 1908.

53 «Davant la tomba oberta», La Campana de Gracia, Barcelona, 26 de septiembre de 1908.

54 SUÁREZ CORTINA, M.: El gorro frigio. Liberalismo, Democracia y Republicanismo en la Restauración. Madrid, Biblioteca Nueva-Sociedad Menéndez Pelayo, 2000, p. 82.

55 TATO Y AMAT, M. 1914: p. 332.
} 
desde ambas fracciones. La condena del atentado contra Cambó y Salmerón, según el órgano del republicanismo malagueño, no debiera mitigar la reprobación de la actuación política de éste:

«Este hecho, lamentable y deplorable, merecedor de la más dura execración, no nos hace borrar ni una línea de lo que tenemos escrito acerca de lo que nosotros conceptuamos como errores políticos del jefe de la Unión Republicana, ni nos hace rectificar en lo más mínimo nuestro criterio de que el debatido asunto de la solidaridad Catalana, exclusivamente de carácter local y circunstancial, no debió nunca hacerse cuestión de partido que pudiera afectar, como ha afectado, a la política general de Unión Republicana; pero esto no es obstáculo para que con la mayor indignación y energía protestemos del atentado contra el Sr. Salmerón y condenemos el hecho como un crimen vulgar, que reclama el más ejemplar castigo „56.

Para el órgano socialista Salmerón era sólo «un símbolo» o apenas «un prestigio» cuya desaparición daba «el último golpe al partido republicano» ${ }^{57}$.

El Pueblo, órgano de la Unión Republicana de Tortosa, dedicó un número extraordinario a la desaparición del dirigente solidario.

El diario republicano La Región Extremeña, al final de su artículo, destaca la buena voluntad del jefe en su acercamiento a la Solidaridad como modelo regenerador: «él creía que, merced a esa Solidaridad, extendiéndola a otras regiones, podría destruirse el caciquismo y llevarse una revolución profunda que transformara y regenerase el país» $\$ 8$.

En Madrid, la humorística portada de Gedeón no duda en reflejar el desmembramiento de la solidaridad ya en el cementerio ${ }^{59}$.

En el diario republicano La Voz de Menorca sólo en la segunda página se dedica un espacio a recordar a Salmerón. Tras un breve resumen de su vida se afirma que su ingreso en la Solidaridad y las luchas «le han acarreado la muerte»:

«¿Ha acertado el señor Salmerón? ¿Ha equivocado? Esto es muy difícil asegurarlo, lo cierto es que Solidaridad en las últimas elecciones hizo lo que no había logrado aún ningún partido español, aniquilar el caciquismo»60.

El semanario radical autonomista gerundense escribe: «Nunca ejerció Salmerón decisiva influencia en la Solidaridad. Debió su jefatura como antes la de los republicanos, con tener altas cualidades de talento para desempeñarla dignamente, al azar»61.

56 «Atentado al Sr. Salmerón», El Popular, Málaga, 20 de abril de 1907, p. 1.

57 «La semana burguesa», El Socialista, 25 de septiembre de 1908.

58 «Salmerón», La Región Extremeña, Badajoz, 22 de septiembre de 1908, p. 1.

59 «En el entierro del ilustre Jefe», Gedeón, Madrid, 27 de septiembre de 1908.

60 «Crónica local. Nicolás Salmerón y Alonso», La Voz de Menorca, Mahón, 21 de septiembre de 1908 , p. 2.

61 «La Jefatura solidaria», Bandera Roja, Gerona, 27 de septiembre de 1908, p. 2. 
A inicios de siglo, desaparecidos Francisco Pi y Eduardo Benot, el federalismo estaba reducido a su mínima expresión y, desde luego, sin las energías de los años ochenta del siglo XIX. En 1904 el blasquismo no dudaba en agredir al federalismo valenciano, la cuota federal que arrastró la Unión fue de unos sesenta casinos y veinticinco periódicos, el cisma catalán orienta la asamblea federal de 1905, y en Cataluña, según Duarte, «el catalanismo corroe las entrañas del partido „62. El órgano portavoz de la Juventud Republicana Federal de Tarragona, termina su reseña perdonando los pasados errores de Salmerón, y lo hace por su tarea al frente de la Solidaridad. Pero, sin embargo, previamente, recuerda a los lectores algunos gestos del pasado de Salmerón considerados poco pertinentes con su jefatura:

«La Senyera Federal que no te per costúm doblegarse a convencionalismos socials recorda que fou en Salmerón qui en 1873 calificà de pirates als Cantonals de Cartagena y algun anys después en el Teatre Principal de Tarragona deia: Si mañana me encontrara con los poderes del 73 con más rigor que a los carlistas perseguiría a los federales» ${ }^{63}$.

Por su parte, la prensa republicana almeriense hizo en su momento una apología de la figura de Salmerón, con titulares como «La muerte del justo», que superaba a la de algunos órganos catalanistas ${ }^{64}$, pero no a la apoteosis de don $\mathrm{Ni}$ colás según la prosa de Gabriel Alomar:

«Salmerón, que ve su obra y su acción purificadas y siente la exclusión benéfica de una plebe incapaz de ser pueblo, y de un hombre en quien se encarnan todos los viejos matonismos nacionales que han hecho estéril y tiránica la obra de la revolución y experimenta el gozo de una ruptura sana y desinfectante con todo lo que deprimía o hacía sospechosa su empresa, goza también la suprema consagración del insulto de los indignos. Y nunca, ¿no es verdad?, nunca se había sentido más radicalmente, más fundamentalmente revolucionario» ${ }^{65}$.

En Málaga la Juventud Republicana hizo pública su orientación por el republicanismo radical. A finales de 1908 celebraron un banquete político y velada por el triunfo de los antisolidarios, por el triunfo de los republicanos de Barcelona y Valencia, «sacando vencedores, en frente de las candidaturas solidaria y clerical, a los candidatos republicanos» ${ }^{66}$.

62 DUARTE, Á.: «La unión republicana de 1903 ¿eslabón o gozne?», en MARTíNEZ LÓPEZ, F. (ed.) Nicolás Salmerón y el republicanismo parlamentario. Madrid, Biblioteca Nueva, 2007, p. 156.

63 «Salmerón», La Seynera Federal, Tarragona, 27 de septiembre de 1908, p. 1.

64 Véanse El Radical, Almería, 22 y 23 de septiembre de 1908, y el número extraordinario de El Pueblo, órgano de la Unión Republicana de Tortosa, del 24 de septiembre de 1908.

65 «A la memoria de D. Nicolás Salmerón», La Cataluña, núm. 52, Barcelona, 26 de septiembre de 1908 , p. 2.

66 «Por el triunfo republicano. El banquete de ayer», El Popular, 29 de diciembre de 1908. En su discurso, el Secretario de la Juventud Republicana, León Belao, hizo unos elogios patrióticos que fueron recogidos por el inspector representante de la autoridad gubernativa, don José García Soler, y que los redactores de El Popular quizá olvidaron transcribir: «León Bela[d]o dice que los republicanos de Barcelona 


\section{CONCLUSIONES}

Las fracturas del republicanismo, o de los distintos republicanismos del momento, fueron proverbiales y casi congénitas con él en sus recurrentes uniones y desuniones. De hecho el conflicto entre solidarios y antisolidarios, como se ha señalado, sólo es una parte de los antagonismos de un republicanismo ya representado fragmentariamente en la Unión de 1903.

Es muy probable que la Unión de 1903 y su Jefatura fuera el cenit de la carrera política de Salmerón, pero quizá lo fuera aún más su generosa y arriesgada visión de una Solidaridad exportable al resto de España para superar la inmoralidad y el caciquismo y, en definitiva, derrocar el sistema. Salmerón percibió la fractura entre el Estado y la Nación, de ahí el movimiento de carácter anticaciquil, no sólo desde una región sino de una como las demás, con el fin de renovar un sistema político corrupto en lo económico y en lo parlamentario. La postura de apoyo a la Solidaridad está cargada de aparentes ambivalencias e incluso de una visión etnocentrista en cuanto a intereses de sectores de la sociedad cercanos al poder. Sin embargo, Salmerón vio en la sociedad catalana una calidad democrática capaz de generar una corriente de moralidad política extrapolable a otras regiones.

La vía de Salmerón no era, desde luego, la veleidad revolucionaria, las antiguas inercias violentas de los jóvenes de la Federación Revolucionaria: se trataba de derribar y superar al régimen vigente por medio de la legalidad y la pureza del sufragio. Esta no era la vía de Lerroux. En cualquier caso, habría que distinguir entre la violencia en Cataluña y el conflicto político dentro de la Unión en el resto de España.

Salmerón tenía presentes los postulados que preconizara la Tercera República francesa, en especial todo aquello «en relación a la importancia del acceso democrático a la instrucción y el papel social de la elite de la cultura, por contraste con el gobierno de la oligarquía económica» ${ }^{67}$. Según Fernando Martínez, el político almeriense «buscó la regeneración y modernización de España y no escatimó esfuezos al final de su vida desde la plataforma política de la Solidaridad Catalana a pesar de la incomprensión de buena parte del republicanismo» ${ }^{68}$.

Se ha querido destacar en este texto, además, cómo con ocasión del óbito del dirigente republicano, las distintas visiones desde la prensa y desde las distintas

han sabido conquistar la bandera Española que los solidarios la tenían tirada en el arroyo". Informe del Jefe de Vigilancia al Gobernador Civil. Banquete de la Juventud Republicana. Málaga, 27 de diciembre de 1908. Véase MUÑOZ ZAFRA, M.: «El calendario republicano local», en MORALES MUÑOZ, M. (ed.) República y modernidad. El republicanismo en los umbrales del siglo XX. Málaga, CEDMA, 2006, p. 181.

${ }^{67}$ DUARTE, Á. y GABRIEL, P.: «¿Una sola cultura política republicana ochocentista en España?, en Ayer, núm. 39, 2000, p. 22.

${ }_{68}$ MARTÍNEZ LÓPEZ, F.: «La redención por el sufragio. La apuesta de Nicolás Salmerón y Alonso en el cambio de siglo (1890-1903)", en MORALES MUÑOZ, M. (ed.) República y modernidad. El republicanismo en los umbrales del siglo XX. Málaga, CEDMA, 2006, p. 64. 
sensibilidades y familias republicanas, construyen simbólicamente en su momento la imagen mítica del jefe republicano, aprovechando el momento para construir e in-corporar el símbolo. No únicamente la imagen mítica del jefe como superviviente, como hoja viva o elemento del calendario republicano a conmemorar ritualmente en los siguientes años.

Otra cuestión sería dilucidar hasta qué punto los «cleavages» que parcelan a la sociedad civil española de comienzos de siglo, eran perceptibles o se reflejaban en las facciones republicanas, y de qué forma estas fracturas se solapaban o eran inconciliables dependiendo del contexto socioeconómico, ideológico o religioso en el que se producían.

Es probable que la generosidad de Salmerón no calculara las consecuencias que su postura podía ocasionar al partido de Unión. Así, eran protagonistas de la ruptura no sólo los federales de dentro y de fuera o los radicales lerrouxistas, sino también el posibilismo reformista de Álvarez, a ello habría que añadir el riesgo de una Solidaridad reducida y controlada por Cambó.

El partido republicano de Salmerón era un órgano de la clase media que perseguía la reforma política, un régimen de equilibrio entre derecho y poder, y la capacitación política del cuarto estado. La crisis del año 1909 traerá como consecuencia la formación de la Conjunción republicano-socialista. La caída de Maura fue festejada con una manifestación el 24 de octubre de 1909, y ante la estatua de Castelar hablaron Rodrigo Soriano, Pablo Iglesias y Juan Sol. La alianza republicano-socialista fue sellada el 7 de noviembre con un mitin en el frontón Jai-Alai. Presidía Benito Pérez Galdós. 